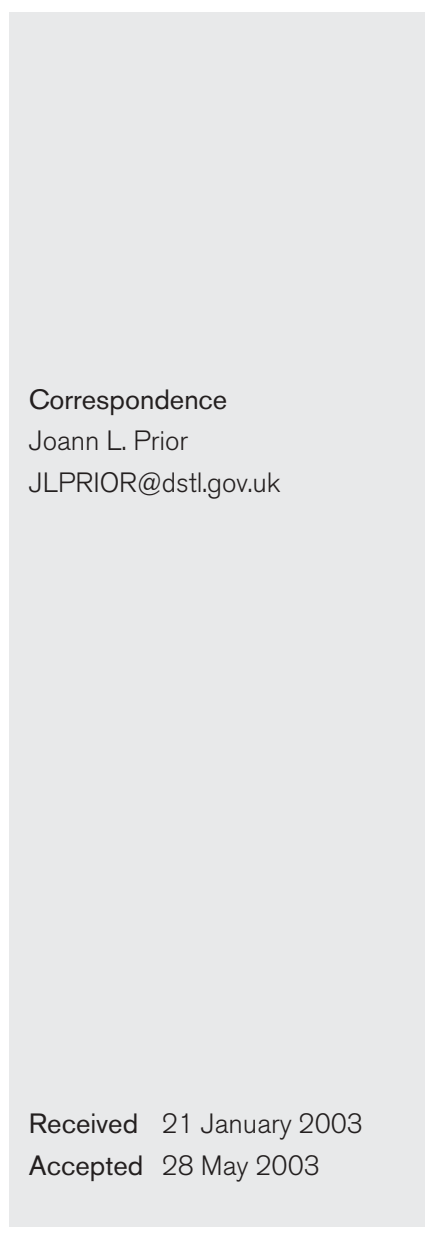

\title{
Characterization of the $\mathrm{O}$ antigen gene cluster and structural analysis of the $\mathrm{O}$ antigen of Francisella tularensis subsp. tularensis
}

\author{
Joann L. Prior, ${ }^{1}$ Richard G. Prior, ${ }^{1}$ Paul G. Hitchen, ${ }^{2}$ Helen Diaper, ${ }^{1}$ \\ Kate F. Griffin, ${ }^{1}$ Howard R. Morris, ${ }^{2,3}$ Anne Dell ${ }^{2}$ and Richard W. Titball ${ }^{1,4}$ \\ ${ }^{1}$ Dstl Porton Down, Salisbury, Wiltshire SP4 OJO, UK \\ ${ }^{2}$ Department of Biological Sciences, Imperial College, London SW7 2AZ, UK \\ ${ }^{3}$ M-SCAN Mass Spectrometry Research and Training Centre, Silwood Park, Ascot SL5 7PZ, UK \\ ${ }^{4}$ Department of Infectious and Tropical Disease, London School of Hygiene and Tropical Medicine, \\ Keppel St., London WC1E 7HT, UK
}

\begin{abstract}
A gene cluster encoding enzymes involved in LPS O antigen biosynthesis was identified from the partial genome sequence of Francisella tularensis subsp. tularensis Schu S4. All of the genes within the cluster were assigned putative functions based on sequence similarity with genes from $\mathrm{O}$ antigen biosynthetic clusters from other bacteria. Ten pairs of overlapping primers were designed to amplify the $\mathrm{O}$ antigen biosynthetic cluster by PCR from nine strains of $F$. tularensis. Although the gene cluster was present in all strains, there was a size difference in one of the PCR products between subsp. tularensis strains and subsp. holarctica strains. LPS was purified from F. tularensis subsp. tularensis Schu $\mathrm{S} 4$ and the $\mathrm{O}$ antigen was shown by mass spectrometry to have a structure similar to that of $F$. tularensis subsp. holarctica strain 15. When LPS from $F$. tularensis subsp. tularensis Schu S4 was used to immunize mice that were then challenged with $F$. tularensis subsp. tularensis Schu S4, an extended time to death was observed.
\end{abstract}

\section{INTRODUCTION}

Francisella tularensis is a small, Gram-negative coccobacillus that causes the zoonotic disease tularaemia. Tularaemia occurs in the Northern hemisphere, with cases reported frequently in Europe, North America, Asia, northern Russia and Japan. Rodents are thought to be the main reservoir of the bacterium, with ticks as one of the main vectors (Stewart, 1998). The genus Francisella includes F. tularensis, Francisella novicida and Francisella philomiragia. F. tularensis has been divided into three subspecies (tularensis, holarctica and mediaasiatica) on the basis of virulence, citrulline ureidase activity and acid production from glycerol (Olsufjev \& Meshcheryakova, 1983; Olsufjev et al., 1959). In addition, it has been suggested that $F$. novicida should also be considered a subspecies of F. tularensis (Hollis et al., 1989). Strains of F. tularensis subsp. tularensis are highly virulent in

Abbreviations: GalNAcAN, 2-acetamido-2-deoxy-D-galacturonamide; QuiNAc, 2-acetamido-2,6-dideoxy-D-glucose; Qui4NFm, 4,6-dideoxy-4formamido-D-glucose.

The GenBank/EMBL/DDBJ accession number for the sequence of the F. tularensis Schu S4 O antigen gene cluster is AY217763. humans, whilst strains belonging to $F$. tularensis subsp. holarctica and subsp. mediaasiatica cause a milder form of the disease.

There have been some limited studies on the structure and immunogenicity of LPS isolated from $F$. tularensis subsp. holarctica (Dreisbach et al., 2000). It is reported that the LPS is less toxic than other Gram-negative LPS (Ancuta et al., 1996; Sandstrom et al., 1992) and that its O antigen contains the rare sugars 2-acetamido-2,6-dideoxy-D-glucose (QuiNAc) and 4,6-dideoxy-4-formamido-D-glucose (Qui4NFm) and two moles of 2-acetamido-2-deoxy-D-galacturonamide (GalNAcAN), to give the repeat structure $4-\alpha$-GalNAcAN$1,4-\alpha$-GalNAcAN-1,3- $\beta$-QuiNAc- $1,2-\beta$-Qui4NFm (Vinogradov et al., 1991). The repeat structure is similar to those found in the $\mathrm{O}$ antigens of Pseudomonas aeruginosa O6 and Shigella dysenteriae type 7 (Knirel et al., 1988; Vinogradov et al., 1987). However, there are no reports of LPS characterization from highly virulent (subsp. tularensis) strains of $F$. tularensis. It is known that animals immunized with LPS from $F$. tularensis subsp. holarctica are fully protected against a subsequent challenge with a subsp. holarctica strain (Fulop et al., 1995), but not against challenge with a subsp. tularensis strain (Fulop et al., 2001). This raises 
the possibility that the LPS from a subsp. holarctica strain is not identical to that of a subsp. tularensis strain. In order to investigate this, we have isolated LPS from F. tularensis strains Schu S4 (subsp. tularensis) and LVS (subsp. holarctica) and compared their structure. We also aimed to elucidate the genetic basis of $\mathrm{O}$ antigen expression in $F$. tularensis strain Schu S4 and to use this information to investigate the distribution of the $\mathrm{O}$ antigen gene cluster in different strains of F. tularensis subsp. tularensis and subsp. holarctica.

\section{METHODS}

Bacterial strains and growth conditions. The following strains were used: F. tularensis subsp. tularensis strains Schu S4, 199 and 041; F. tularensis subsp. holarctica strains LVS, 200, 025, 075 and HN63. Strains were cultured at $37^{\circ} \mathrm{C}$ on BCGA agar for $48 \mathrm{~h}$.

LPS purification. LPS was purified from $F$. tularensis subsp. tularensis Schu S4 and F. tularensis subsp. holarctica LVS using a hot-phenol and water extraction method (Westphal \& Jann, 1965). In brief, LPS was extracted from freeze-dried bacteria with $45 \%$ phenol at $67{ }^{\circ} \mathrm{C}$. The mixture was stirred for $30 \mathrm{~min}$ and centrifuged. The resulting pellet was re-extracted and the water phases from the two extractions were dialysed against water for 3 days. The resulting solution was ultracentrifuged and treated with RNase and proteinase $\mathrm{K}$.

Gel electrophoresis and silver staining. Glycine gel electrophoresis was performed according to the buffer system of Laemmli (1970) using a $12.5 \%$ separating gel with a $4.5 \%$ stacking gel. Aliquots $(10 \mu \mathrm{l})$ of each sample were electrophoresed for approx. $2 \mathrm{~h}$ at $100 \mathrm{mV}$ in the Miniprotean II slab system (Bio-Rad). Gels were silver-stained according to the method of Chart (1994), with the oxidation step increased to $10 \mathrm{~min}$. To achieve comparable staining, forty times more F. tularensis LPS was loaded than Escherichia coli K325 LPS.

Nucleotide sequence analysis. The sequence encoding the $\mathrm{O}$ antigen biosynthetic cluster was identified from the F. tularensis Schu S4 partial genome sequence (Prior et al., 2001), available at http://artedi.ebc. uu.se/Projects/Francisella/. Known protein sequences (obtained from GenBank) involved in the biosynthesis of the $\mathrm{O}$ antigen of other bacteria were used to probe the partial genome sequence data using TBLASTN (Altschul et al., 1997). The contig containing the putative $\mathrm{O}$ antigen gene cluster was extracted and subsequently analysed using the annotation tool ARTEMIS (http://www.sanger.ac.uk/Software/Artemis).

The protein sequences encoded by the putative $\mathrm{O}$-antigen flippase gene $(w z x)$ and O-antigen polymerase gene $(w z y)$ were analysed for transmembrane helices using TMHMM (Sonnhammer et al., 1998).

PCR analysis of the putative $\mathbf{O}$ antigen gene cluster. DNA was prepared from the $F$. tularensis strains listed above by phenol extraction as described by Karlsson et al. (2000). Ten pairs of overlapping PCR primers were designed using the DNAstar program PrimerSelect to amplify the whole of the putative $\mathrm{O}$ antigen gene cluster in approximate $2 \mathrm{~kb}$ segments. The primers were designed with annealing temperatures ranging from 42 to $59{ }^{\circ} \mathrm{C}$, although all were used successfully at $49{ }^{\circ} \mathrm{C}$.

PCR amplification using each pair of primers with each template DNA was carried out in the following mixture: $1 \times$ PCR buffer (including 1.5 $\mathrm{mM} \mathrm{MgCl} 2$ ), $0 \cdot 2 \mathrm{mM}$ dNTPs, $2 \cdot 5 \mathrm{mM}$ forward primer, $2 \cdot 5 \mathrm{mM}$ reverse primer, $2 \cdot 0 \mu$ template DNA, $0.5 \mathrm{U}$ Taq polymerase and filtered sterile water to a final volume of $20 \mu \mathrm{l}$. The reaction mixtures were incubated at $90{ }^{\circ} \mathrm{C}$ for $1 \mathrm{~min}$ and then cycled at $90{ }^{\circ} \mathrm{C}$ for $1 \mathrm{~min}, 49^{\circ} \mathrm{C}$ for $1 \mathrm{~min}$ and $72{ }^{\circ} \mathrm{C}$ for $145 \mathrm{~s}$ for 30 cycles, with a final incubation at $72{ }^{\circ} \mathrm{C}$ for $10 \mathrm{~min}$.
PCR products were visualized on $0.5 \%$ agarose gels, with ethidium bromide staining. PCR buffer, dNTPs and polymerase were from Roche. PCR primers were synthesized by MWG-Biotech.

Cloning of PCR products. PCR products amplified from Schu S4, HN63 and LVS DNA using primer pair 8 were cloned into pGEM-T easy (Promega) for sequence analysis. Ligated DNA was transformed in $E$. coli JM109 chemically competent cells (Promega) and putative clones were screened using both colony PCR and digestion with restriction endonucleases. All DNA manipulations, including ligations, transformations, colony PCR, restriction endonuclease digestions and agarose gel electrophoresis, were carried out according to standard methods (Sambrook et al., 1989). Purification of PCR products from agarose gel was achieved using the QIAquick gel extraction kit (Qiagen) according to the manufacturer's instructions.

The three constructs were sequenced using the dideoxynucleotide chain-termination method (Sanger et al., 1977) with universal primers. Each sequence was compared and the BLAST (Altschul et al., 1990) function of the ARTEMIS software package was used for similarity searches in the locally held GenBank databases to identify the functions of the different regions of DNA.

Mass spectrometric (MS) analysis of the $\mathbf{O}$ antigen molecule. Polysaccharide was released in aqueous $1 \%$ acetic acid at $100{ }^{\circ} \mathrm{C}$ for $2 \mathrm{~h}$ and then reduced with $\mathrm{NaBH}_{4}\left(10 \mathrm{mg} \mathrm{ml}^{-1}\right)$ in $2 \mathrm{M} \mathrm{NH}_{3}$ for $2 \mathrm{~h}$ at room temperature (Hitchen et al., 2002). Excess borates were removed by repeated additions $(\times 4)$ of $10 \%$ acetic acid in methanol. Methylation using the sodium hydroxide procedure was performed as described by Dell et al. (1994). After derivatization, the reaction products were purified on a Sep-Pak $\mathrm{C}_{18}$ column (Waters) as described by Dell et al. (1994).

Matrix-assisted laser desorption/ionization (MALDI)-MS was performed on a Perseptive Biosystems Voyager Elite mass spectrometer with delayed extraction. Samples were dissolved in $200 \mu \mathrm{l}$ methanol/ water $(80: 20, \mathrm{v} / \mathrm{v})$ and aliquots $(0.5 \mu \mathrm{l})$ of the resulting solutions were analysed using a matrix of 2,5-dihydroxybenzoic acid. Angiotensin and insulin B chain were external calibrants.

Immunization with LPS and protection studies. The ability of $F$. tularensis subsp. tularensis Schu S4 LPS to protect BALB/c mice from a $F$. tularensis subsp. tularensis challenge was determined by immunizing a group of six female BALB/c mice (Charles River Laboratories) with LPS purified as above. On days 0,7 and 14, mice were dosed intraperitoneally with $50 \mu \mathrm{g}$ LPS in PBS. They were challenged 21 days after the last immunization with 10 c.f.u. F. tularensis subsp. tularensis Schu S4 by the subcutaneous route, delivered in $0 \cdot 1 \mathrm{ml}$. All procedures were carried out in accordance with Home Office guidelines.

\section{RESULTS AND DISCUSSION}

\section{LPS purification}

The hot-phenol/water extraction method was used to purify LPS from $2 \cdot 2 \mathrm{~g}$ freeze-dried cells of $F$. tularensis subsp. tularensis Schu S4. This resulted in $7 \mathrm{mg}$ LPS, a yield of $0 \cdot 3 \%$. LPS from $F$. tularensis subsp. holarctica LVS was extracted from $1.25 \mathrm{~g}$ freeze-dried bacteria using the same method. This resulted in $2 \mathrm{mg}$ LPS, a yield of $0 \cdot 16 \%$. To obtain visible silver-staining of LPS after SDS-PAGE, the oxidation step was increased from 5 to $10 \mathrm{~min}$ (Fig. 1). 


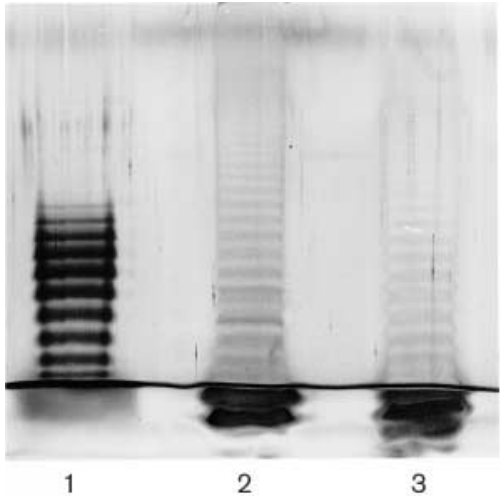

Fig. 1. SDS-PAGE of LPS isolated from various strains. Lanes: 1, E. coli strain K325 $(1.25 \mu \mathrm{g}) ; 2$, F. tularensis subsp. holarctica LVS (50 $\mu \mathrm{g}), 3$, F. tularensis subsp. tularensis Schu S4 (50 $\mu \mathrm{g})$.

\section{MS analysis of the $\mathbf{O}$ antigen molecule}

The composition of the $\mathrm{O}$ antigen expressed by $F$. tularensis subsp. tularensis Schu S4 was determined by MS in order to allow direct comparison with the previously reported composition of the $\mathrm{O}$ antigen from $F$. tularensis subsp. holarctica strain 15. Mild hydrolysis was used to cleave lipid A from the core glycan. The products of this hydrolysis are expected to be free core and $\mathrm{O}$ antigen-substituted core of varying $\mathrm{O}$ antigen chain length, together with lipid A. Lipid A was not observed in the following MS experiments because it was separated from the free glycans during the Sep-Pak purification stage.

Samples were reduced and methylated prior to MALDI-MS analyses and data attributable to the derivatized $\mathrm{O}$ antigen plus core oligosaccharide are shown in Fig. 2. The data suggest that there are two core structures. The larger core gives $[\mathrm{M}+\mathrm{Na}]^{+}$signals at $\mathrm{m} / z 1422$ and 1376 , corresponding to the composition $\mathrm{HexNAcHex}{ }_{4} \mathrm{Kdo}$. The signals at $\mathrm{m} / \mathrm{z}$ 1218 and 1172 correspond to core containing one fewer hexose residue (i.e. HexNAcHex 3 Kdo). The signals at $\mathrm{m} / \mathrm{z}$ 1376 and 1172 are -46 satellites from $\mathrm{m} / z 1422$ and 1218 , respectively, which we have previously shown to be diagnostic of oligosaccharides containing a reducing Kdo residue (Dell et al., 1990) expected for the products of mild acid hydrolysis of LPS. Previous work by Vinogradov et al. (1991) has shown that the $\mathrm{O}$ antigen repeat unit of $F$. tularensis subsp. holarctica strain 15 has the composition QuiNAc, Qui4NFm and two moles of GalNAcAN. The signals at $\mathrm{m} / \mathrm{z}$ $2382[\mathrm{M}+\mathrm{Na}]^{+}$and $m / z 2336(-46$ satellite) are consistent with the larger core (HexNAcHex $\left.{ }_{4} \mathrm{Kdo}\right)$ plus one $\mathrm{O}$ antigen repeat unit, where the $\mathrm{O}$ antigen unit has the composition QuiNAc(GalNAcAN) ${ }_{2}$ Qui4NFm. An additional one and two $\mathrm{O}$ antigen repeat units would give rise to the signals at $\mathrm{m} / \mathrm{z} 3342$ and 4302 , respectively. Clusters consistent with one and two further repeat units are visible above the base line (Fig. 2 inset; $m / z 5262$ and 6222). The two spectra (Fig. 2a, b) show remarkably similar data. These data suggest that the two strains have identical $\mathrm{O}$ antigen repeats.
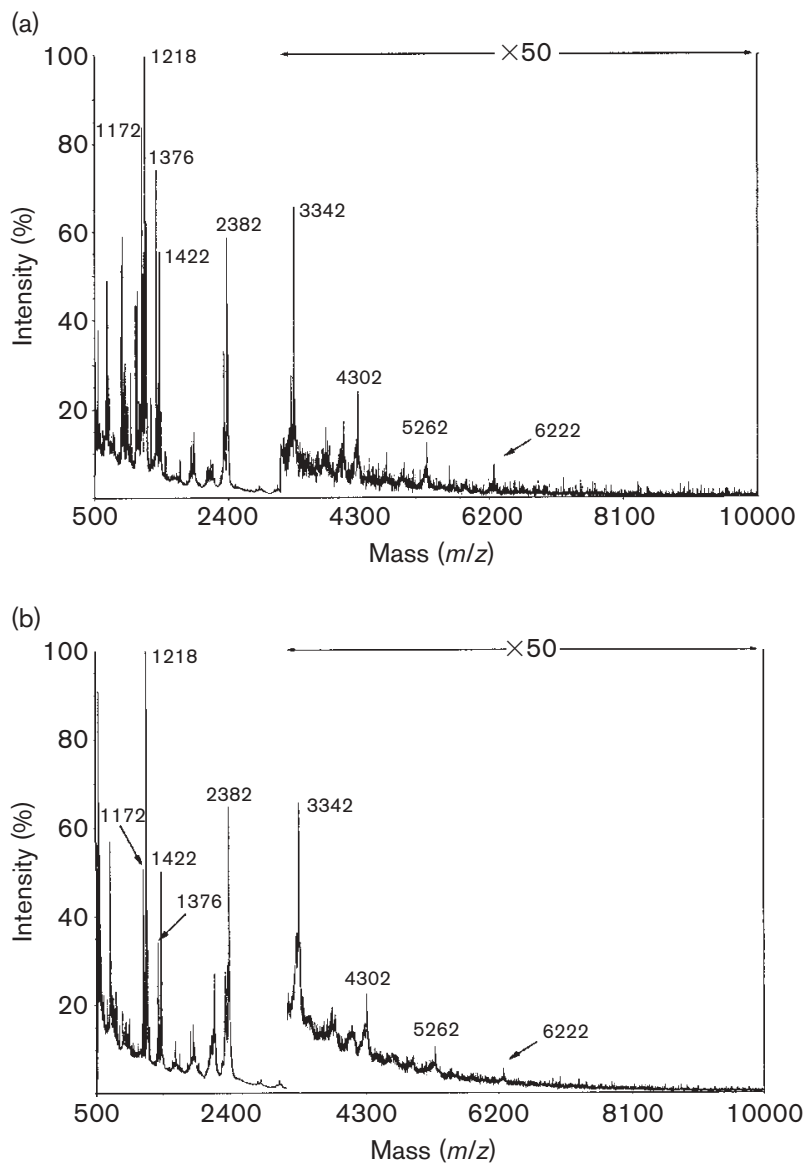

Fig. 2. MALDI-MS of methylated polysaccharide from F. tularensis strains Schu4 (a) and LVS (b). Polysaccharides were released by mild acid hydrolysis, reduced and methylated. Derivatized polysaccharide was purified by Sep-Pak and the $75 \%$ (v/v) aqueous acetonitrile fractions were analysed by MALDI-MS.

\section{Analysis of $\boldsymbol{F}$. tularensis putative $\mathbf{O}$ antigen biosynthetic gene cluster}

The $F$. tularensis putative $\mathrm{O}$ antigen biosynthetic gene cluster was found to be approximately $17 \mathrm{~kb}$ in length and was predicted to contain 15 genes involved in $\mathrm{O}$ antigen biosynthesis (Table 1). The cluster was flanked by two transposases (Fig. 3), raising the possibility that the cluster may have been horizontally acquired. The genes $\operatorname{man} C$ and manB were located downstream of the second transposase and are probably not involved in biosynthesis of the $\mathrm{O}$ antigen, as mannose was not found to be a component of the F. tularensis $\mathrm{O}$ antigen, nor is it likely to be one of the intermediate products required for its synthesis. The manC and $\operatorname{man} B$ genes may have been involved in biosynthesis of the $\mathrm{O}$ antigen in an ancestor of $F$. tularensis.

Fig. 3 also shows the $\mathrm{G}+\mathrm{C}$ content plot of the cluster, using a window size of 500 bases. The overall $\mathrm{G}+\mathrm{C}$ content of this region $(31.27 \%)$ was slightly lower than the mean genome content of approximately $33 \%$ (Prior et al., 2001). The 
Table 1. Putative $O$ antigen genes and gene products of $F$. tularensis subsp. tularensis Schu S4

Similar protein matches are based on the highest identity across the whole protein.

\begin{tabular}{|c|c|c|c|c|c|c|}
\hline Putative gene product & Length (aa) & Putative function & Similar protein & Identity (\%) & Organism & Accession no. \\
\hline \multirow[t]{2}{*}{ Transposase } & 247 & Hypothetical protein & & $37 \cdot 1$ & Mesorhizobium loti & BAB53737 \\
\hline & & Transposase & & $35 \cdot 2$ & Vibrio salmonicida & CAC35348 \\
\hline \multirow[t]{2}{*}{ WbtA } & 578 & Sugar epimerase & PglF & $46 \cdot 8$ & Campylobacter jejuni & AAD51388 \\
\hline & & & WbpM & $41 \cdot 7$ & Pseudomonas aeruginosa & AAD45269 \\
\hline \multirow[t]{2}{*}{ WbtB } & 205 & Galactosyl transferase & Cps9F & $64 \cdot 7$ & Streptococcus suis & AAF18949 \\
\hline & & Glycosyl transferase & & $41 \cdot 3$ & Pseudomonas aeruginosa & H83366 \\
\hline \multirow[t]{2}{*}{ WbtC } & 263 & UDP-glucose 4-epimerase & & $47 \cdot 5$ & Bacillus halodurans & BAB07434 \\
\hline & & & $\mathrm{WbpV}$ & $32 \cdot 8$ & Pseudomonas aeruginosa & AAF23991 \\
\hline \multirow[t]{2}{*}{ WbtD } & 363 & Sugar transferase & & $39 \cdot 3$ & Streptococcus pneumoniae & САB05923 \\
\hline & & & WbpU & $30 \cdot 4$ & Pseudomonas aeruginosa & AAF23992 \\
\hline \multirow[t]{2}{*}{ WbtE } & 436 & LPS biosynthesis & WbgT & $53 \cdot 6$ & Shigella sonnei & $\mathrm{T} 44520$ \\
\hline & & Dehydrogenase & WbpO & $52 \cdot 8$ & Pseudomonas aeruginosa & AAF23997 \\
\hline $\mathrm{WbtF}$ & 323 & C 4-epimerase & WbpP & $51 \cdot 2$ & Pseudomonas aeruginosa & AAF23998 \\
\hline Wzy & 409 & Membrane protein/O-antigen polymerase & & $24 \cdot 6$ & Clostridium acetobutylicum & AAK81105 \\
\hline WbtG & 366 & Transferase & WbpT & $27 \cdot 9$ & Pseudomonas aeruginosa & AAF23993 \\
\hline $\mathrm{WbtH}$ & 628 & Asparagine synthetase & WbpS & $48 \cdot 5$ & Pseudomonas aeruginosa & AAF24002 \\
\hline \multirow[t]{2}{*}{ WbtI } & 360 & Sugar transaminase/perosamine synthetase & & $59 \cdot 9$ & Clostridium acetobutylicum & AAK80306 \\
\hline & & & & $43 \cdot 1$ & Pseudomonas aeruginosa & AAK15326 \\
\hline WbtJ & 241 & Formyl transferase & Unnamed & $40 \cdot 4$ & Mycobacterium tuberculosis & AAK47850 \\
\hline Wzx & 495 & O-Antigen flippase & Wzx & $28 \cdot 9$ & Escherichia coli & AAL67558 \\
\hline WbtK & 286 & Glycosyl transferase & & $36 \cdot 7$ & Clostridium acetobutylicum & AAK80304 \\
\hline WbtL & 294 & Glucose-1-phosphate thymidylyltransferase & Unnamed & $67 \cdot 7$ & Actinobacillus actinomycetemcomitans & Т00103 \\
\hline \multirow[t]{2}{*}{ WbtM } & 348 & dTDP-D-glucose 4,6-dehydratase & $\mathrm{RmlB}$ & $63 \cdot 9$ & Legionella pneumophila & CAB65206 \\
\hline & & dTDP-D-glucose 4,6-dehydratase & & $56 \cdot 3$ & Pseudomonas aeruginosa & B83000 \\
\hline Transposase & 126 & Transposase & & $29 \cdot 7$ & Streptococcus pneumoniae & AAK76082 \\
\hline ManC & 468 & Mannose-1-phosphate guanylyltransferase & ManC & $50 \cdot 4$ & Vibrio cholerae & Q07024 \\
\hline ManB & 494 & Phosphomannomutase & ManB & $45 \cdot 9$ & Salmonella choleraesuis & Q00330 \\
\hline
\end{tabular}




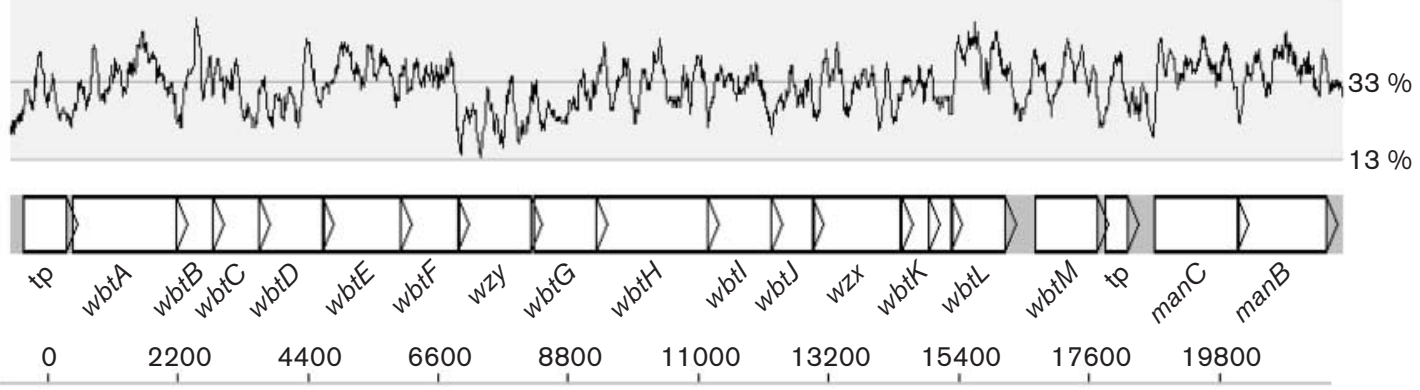

Fig. 3. Genetic organization of the $O$ antigen gene cluster in F. tularensis subsp. tularensis Schu S4.

central section of the cluster, from $w z y$ to $w b t K$, had an even lower $\mathrm{G}+\mathrm{C}$ content. Downstream from $\operatorname{man} C$, on the opposite strand, the genes for the transcription termination factor rho and thioredoxin were identified.

The $\mathrm{O}$ antigen repeat unit of $F$. tularensis (Vinogradov et al., 1991) is shown in Fig. 4, together with the putative role of the genes involved in $\mathrm{O}$ antigen biosynthesis. Based on homology to other LPS and sugar biosynthetic genes, in particular to genes from $P$. aeruginosa serotype O6, which expresses a similar O antigen repeat structure (Knirel et al., 1985), the putative roles of the gene products have been assigned. It is proposed that the biosynthesis of QuiNAc involves WbtA, a dehydratase and $\mathrm{WbtC}$, which showed sequence similarity to known UDP-glucose 4-epimerases. WbtA and WbtC showed sequence similarity to $\mathrm{WbpM}$ and $\mathrm{WbpV}$ of $P$. aeruginosa strain O6. Both of these enzymes are thought to be involved in QuiNAc biosynthesis and have been shown to be essential for $\mathrm{O}$ antigen synthesis in $P$. aeruginosa strain O6 (Belanger et al., 1999). WbtE, $\mathrm{WbtF}$ and $\mathrm{WbtH}$ are proposed to be involved in GalNAcAN biosynthesis. WbtF showed sequence similarity to known UDP-glucose 4-epimerases, including WbpP in P. aeruginosa and VipB in Salmonella typhi. WbtE showed sequence similarity to $\mathrm{WbpO}$ and VipA, which are UDP-GalNAc dehydrogenases involved in the formation of 2-acetamido-2-deoxy-D-galactouronic acid (GalNAcA) in

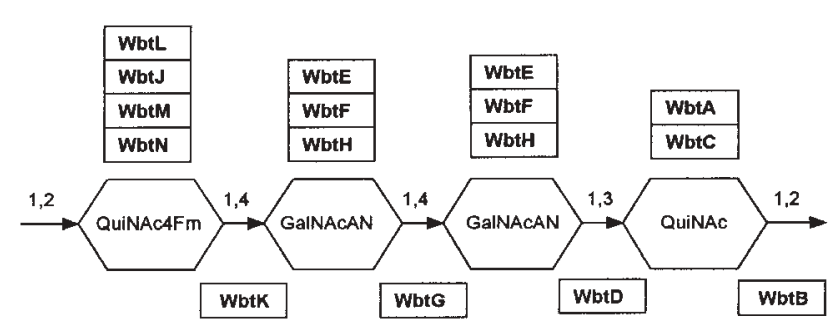

Fig. 4. Schematic structure of an $O$ antigen subunit of $F$. tularensis subsp. tularensis Schu S4 and the assignment of putative functions to the predicted products of the $\mathrm{O}$ antigen gene cluster. A single $\mathrm{O}$-unit is shown, with sugar residues and glycosidic linkages indicated. QuiNAc4Fm, 4,6-dideoxy-4-formamido-D-glucose; GalNAcAN, 2acetamido-2-deoxy-D-galacturonamide; QuiNAc, 2-acetamido-2,6dideoxy-D-glucose.
P. aeruginosa and Salmonella typhi, respectively (Hashimoto imoto et al., 1993; Zhao et al., 2000). WbtH had sequence similarity to glutamine amidotransferases, including $\mathrm{WbpS}$ of $P$. aeruginosa serotype O6, which may be involved in the formation of the GalNAcAN amido group. Biosynthesis of the fourth sugar, Qui4NFm, probably requires WbtI, WbtJ, $\mathrm{WbtL}$ and WbtM. Sequence similarity suggests that WbtL may be involved in the formation of the activated sugar dTDP-D-glucose, with WbtM functioning as a dTDP-Dglucose 4,6-dehydratase. WbtI is proposed to be involved in Qui4NFm amination, since it shows sequence similarity to RfbE from Vibrio cholerae, a perosamine synthetase (Albermann \& Piepersberg, 2001). Finally, WbtJ is likely to be responsible for the addition of the $N$-formyl moiety, showing significant sequence similarity to formyltransferases.

Specific glycosyltransferases are required to form the oligosaccharide units of the $\mathrm{O}$ antigen repeat. Four glycosyltransferases would be necessary for the synthesis of each $\mathrm{O}$ antigen unit in F. tularensis. Based on sequence similarity to known glycosyltransferases, $\mathrm{WbtB}$ is proposed to mediate the addition of QuiNAc to undecaprenyl phosphate (Und-P) to initiate $\mathrm{O}$ antigen biosynthesis. $\mathrm{WbtD}$ and $\mathrm{WbtG}$ are probable GalNAcAN transferases, possibly involved in the addition of the two consecutive GalNAcAN residues onto the $\mathrm{O}$ antigen unit. WbtD shows sequence similarity to $\mathrm{WbpU}$ of $P$. aeruginosa strain $\mathrm{O} 6$, proposed to transfer 2-formamido2-deoxy-D-galactouronamide (GalNFmAN) onto QuiNAc (Belanger et al., 1999). WbtG shows sequence similarity to WbpT of $P$. aeruginosa, which is thought to be involved in addition of GalNAcA to GalNFmAN (Belanger et al., 1999). $\mathrm{WbtK}$ is probably the fourth glycosyltransferase, which adds 4,6-dideoxy-4-formamido-D-glucose (QuiNA4Fm) to complete the tetrasaccharide $\mathrm{O}$ unit.

Within the F. tularensis $\mathrm{O}$ antigen gene cluster, there were no polynucleotide repeats associated with slipped-strand mispairing that could explain the phase variation of LPS observed by other workers (Cowley et al., 1996).

There are two main $\mathrm{O}$ antigen synthesis modes, $\mathrm{O}$-antigen polymerase $(w z y)$-dependent and $w z y$-independent. Two genes in the $F$. tularensis $\mathrm{O}$ antigen gene cluster would 
encode proteins with a high degree of sequence similarity to Wzy and Wzx, suggesting that transportation and polymerization of the $\mathrm{O}$ antigen is via a $w z y$-dependent pathway.

The inability to identify a gene that could encode a Wzz homologue, an $\mathrm{O}$ antigen chain length regulator, probably means that the chain length is determined by some other mechanism in F. tularensis. This may not be unusual, as many bacterial species have an LPS and $\mathrm{O}$ antigen that would require $w z y$-dependent synthesis, but Wzz homologues have not been identified in all of them.

\section{PCR analysis of the 0 antigen gene cluster}

To determine whether the $\mathrm{O}$ antigen gene cluster was present in different strains of $F$. tularensis subsp. tularensis and subsp. holarctica, ten pairs of PCR primers were designed in order to amplify overlapping regions of the putative $\mathrm{O}$ antigen gene cluster. Nine of the PCR products (derived using primer sets 1-7, 9 and 10) from each template DNA appeared to be the same size in all strains when examined by agarose gel electrophoresis (not shown).

PCR using primer pair 8 revealed a difference in size between the DNA fragments amplified from subsp. tularensis strains and subsp. holarctica. These fragments were cloned and sequence analysis of this region from the subsp. tularensis strain Schu S4 and the subsp. holarctica strains HN63 and LVS showed that the deletion in Schu S4 occurs at the beginning of a putative transposase that is similar to IS630spn 1 transposase ORF 1 of Streptococcus pneumoniae. The subsp. tularensis strains show a deletion of 303 nucleotides when compared with subsp. holarctica strains (including LVS). The overall similarity between the subsp. tularensis and subsp. holarctica clusters seems to indicate that the transposase insertion took place in F. tularensis before division of the subspecies. Partial deletion of the transposase would have the effect of stabilizing this region of DNA, as this enzyme is necessary for insertion events to take place (Rubin et al., 2001; Sangari et al., 2000). The difference in this region could be utilized to devise diagnostic systems for discriminating subsp. tularensis from subsp. holarctica strains.

\section{Protection studies}

When animals were immunized with LPS extracted from F. tularensis subsp. holarctica strain LVS and challenged with F. tularensis subsp. tularensis strain Schu S4, no protection was observed (Fulop et al., 2001). To determine whether this was due to a difference in LPS composition, mice were immunized with F. tularensis subsp. tularensis Schu S4 LPS and challenged with F. tularensis subsp. tularensis Schu S4. At the challenge dose of 10 c.f.u. (10 MLD), the immunized group demonstrated a significantly $(P=0 \cdot 01)$ delayed time to death (mean increase of $64 \mathrm{~h}$ ) compared with the unimmunized control group. Work carried out previously by Fulop et al. (2001) with mice immunized with LPS from F. tularensis subsp. holarctica LVS produced similar results, with an extended time to death of $24 \mathrm{~h}$ when animals were subsequently challenged with 10 c.f.u. F. tularensis subsp. tularensis Schu S4. These findings indicate that the LPS from F. tularensis subsp. tularensis and F. tularensis subsp. holarctica have similar immunological properties.

\section{ACKNOWLEDGEMENTS}

A. D. and H. R. M. would like to acknowledge the BBSRC and Wellcome Trust for financial support. The authors would like to thank Drs K. Isherwood and J. Ellis for supplying DNA from the F. tularensis strains used in this work and Mrs D. Rodgers and Mr D. Rawkins for technical assistance.

\section{REFERENCES}

Albermann, M. \& Piepersberg, W. (2001). Expression and identification of the RfbE protein from Vibrio cholerae $\mathrm{O} 1$ and its use for the enzymatic synthesis of GDP-D-perosamine. Glycobiology 11, 655-661.

Altschul, S. F., Gish, W., Miller, W., Myers, E. W. \& Lipman, D. J. (1990). Basic local alignment search tool. J Mol Biol 215, 403-410.

Altschul, S. F., Madden, T. L., Schäffer, A. A., Zhang, J., Zhang, Z., Miller, W. \& Lipman, D. J. (1997). Gapped BLAST and PSI-BLAST: a new generation of protein database search programs. Nucleic Acids Res 25, 3389-3402.

Ancuta, P., Pedron, T., Girard, R., Sandstrom, G. \& Chaby, R. (1996). Inability of the Francisella tularensis lipopolysaccharide to mimic or to antagonize the induction of cell activation by endotoxins. Infect Immun 64, 2041-2046.

Belanger, M., Burrows, L. L. \& Lam, J. S. (1999). Functional analysis of genes responsible for the synthesis of the B-band $\mathrm{O}$ antigen of Pseudomonas aeruginosa serotype O6 lipopolysaccharide. Microbiology 145, 3505-3521.

Chart, H. (1994). LPS: isolation and characterization. In Methods in Practical Laboratory Bacteriology, pp. 11-20. Boca Raton, FL: CRC Press.

Cowley, S., Myltseva, S. V. \& Nano, F. E. (1996). Phase variation in Francisella tularensis affecting intracellular growth, lipopolysaccharide antigenicity and nitric oxide production. Mol Microbiol 20, 867-874.

Dell, A., Azadi, P., Tiller, P., Thomas-Oates, J., Jennings, H. J., Beurret, M. \& Michon, F. (1990). Analysis of oligosaccharide epitopes of meningococcal lipopolysaccharides by fast-atom-bombardment mass spectrometry. Carbohydr Res 200, 59-76.

Dell, A., Reason, A. J., Khoo, K.-H., Panico, M., McDowell, R. A. \& Morris, H. R. (1994). Mass spectrometry of carbohydrate-containing biopolymers. Methods Enzymol 230, 108-132.

Dreisbach, V. C., Cowley, S. \& Elkins, K. L. (2000). Purified lipopolysaccharide from Francisella tularensis live vaccine strain (LVS) induces protective immunity against LVS infection that requires B cells and gamma interferon. Infect Immun 68, 1988-1996.

Fulop, M. J., Manchee, R. J. \& Titball, R. W. (1995). Role of lipopolysaccharide and a major outer membrane protein from Francisella tularensis in the induction of immunity against tularemia. Vaccine 13, $1220-1225$

Fulop, M. J., Mastroeni, P., Green, M. \& Titball, R. W. (2001). Role of antibody to lipopolysaccharide in protection against low- and highvirulence strains of Francisella tularensis. Vaccine 19, 4465-4472.

Hashimoto, Y., Li, N., Yokoyama, H. \& Ezaki, T. (1993). Complete nucleotide sequence and molecular characterization of $\mathrm{ViaB}$ region encoding Vi antigen in Salmonella typhi. J Bacteriol 175, 4456-4465.

Hitchen, P. G., Prior, J. L., Oyston, P. C., Panico, M., Wren, B. W., Titball, R. W., Morris, H. R. \& Dell, A. (2002). Structural characterization of lipooligosaccharide (LOS) from Yersinia pestis: regulation of LOS structure by the PhoPQ system. Mol Microbiol 44, 1637-1650. 
Hollis, D. G., Weaver, R. E., Steigerwalt, A. G., Wenger, J. D., Moss, C. W. \& Brenner, D. J. (1989). Francisella philomiragia comb. nov. (formerly Yersinia philomiragia) and Francisella tularensis biogroup novicida (formerly Francisella novicida) associated with human disease. J Clin Microbiol 27, 1601-1608.

Karlsson, J., Prior, R. G., Williams, K. \& 16 other authors (2000). Sequencing of the Francisella tularensis strain Schu 4 genome reveals the shikimate and purine metabolic pathways, targets for the construction of a rationally attenuated auxotrophic vaccine. Microb Comp Genomics $5,25-39$

Knirel, Y. A., Vinogradov, E. V., Shashkov, A. S., Dmitriev, B. A., Kochetkov, N. K., Stanislavsky, E. S. \& Mashilova, G. M. (1985). Somatic antigens of Pseudomonas aeruginosa. The structure of the Ospecific polysaccharide chains of lipopolysaccharides of $P$. aeruginosa serogroup O4 (Lanyi) and related serotype O6 (Habs) and immunotype 1 (Fisher). Eur J Biochem 150, 541-550.

Knirel, Y. A., Dashunin, V. V., Shashkov, A. S., Kochetkov, N. K., Dmitriev, B. A. \& Hofman, I. L. (1988). Somatic antigens of Shigella: structure of the O-specific polysaccharide chain of the Shigella dysenteriae type 7 lipopolysaccharide. Carbohydr Res 179, 51-60.

Laemmli, U. K. (1970). Cleavage of structural proteins during the assembly of the head of bacteriophage T4. Nature 227, 680-685.

Olsufjev, N. G. \& Meshcheryakova, I. S. (1983). Subspecific taxonomy of Francisella tularensis McCoy and Chapin 1912. Int J Syst Bacteriol 33, 872-874.

Olsufjev, N. G., Emelyanova, O. S. \& Dunaeva, T. N. (1959). Comparative study of strains of B. tularense in the Old and New World and their taxonomy. J Hyg Epidemiol Microbiol Immunol 3, 138-149.

Prior, R. G., Klasson, L., Larsson, P. \& 9 other authors (2001). Preliminary analysis and annotation of the partial genome sequence of Francisella tularensis strain Schu 4. J Appl Microbiol 91, 614-620.

Rubin, E., Lithwick, G. \& Levy, A. A. (2001). Structure and evolution of the hAT transposon superfamily. Genetics 158, 949-957.
Sambrook, J., Fritsch, E. F. \& Maniatis, T. (1989). Molecular Cloning: a Laboratory Manual, 2nd edn. Cold Spring Harbor, NY: Cold Spring Harbor Laboratory.

Sandstrom, G., Sjostedt, A., Johansson, T., Kuoppa, K. \& Williams, J. C. (1992). Immunogenicity and toxicity of lipopolysaccharide from Francisella tularensis LVS. FEMS Microbiol Immunol 5, 201-210.

Sangari, F. J., Bachli, M., Bermudez, L. E. \& Bodmer, T. (2000). Characterization of IS666, a newly described insertion element of Mycobacterium avium. Microb Comp Genomics 5, 181-188.

Sanger, F., Nicklen, S. \& Coulson, A. R. (1977). DNA sequencing with chain-terminating inhibitors. Proc Natl Acad Sci U S A 74, 5463-5467.

Sonnhammer, E. L. L., von Heijne, G. \& Krogh, A. (1998). A hidden Markov model for predicting transmembrane helices in protein sequences. In The Sixth International Conference on Intelligent Systems for Molecular Biology, pp. 175-182. Edited by J. Glasgow, T. Littlejohn, F. Major, R. Lathrop, D. Sankoff \& C. Sensen. Menlo Park, CA: AAAI Press.

Stewart, S. J. (1998). Tularemia. In Topley and Wilson's Microbiology and Microbial Infections, 9th edn, pp. 949-954. Edited by L. Collier, A. Balows \& M. Sussman. London: Arnold.

Vinogradov, E. V., Knirel, Y. A., Shashkov, A. S. \& Kochetkov, N. K. (1987). Determination of the degree of amidation of 2-deoxy-2formamido-D-galacturonic acid in O-specific polysaccharides of Pseudomonas aeruginosa $\mathrm{O} 4$ and related strains. Carbohydr Res 170, C1-C4.

Vinogradov, E. V., Shashkov, A. S., Knirel, Y. A., Kochetkov, N. K., Averin, S. F., Goncharova, O. V. \& Khlebnikov, V.S. (1991). Structure of the O-antigen of Francisella tularensis strain 15. Carbohydr Res 214, 289-297.

Westphal, O. \& Jann, K. (1965). Bacterial lipopolysaccharides. Extraction with phenol-water and further applications of the procedure. Methods Carbohydr Chem 5, 83-91.

Zhao, X., Creuzenet, C., Belanger, M., Egbosimba, E., Li, J. \& Lam, J. S. (2000). WbpO, a UDP- $N$-acetyl-D-galactosamine dehydrogenase from Pseudomonas aeruginosa serotype O6. J Biol Chem 275, 33252-33259. 